\title{
Transportation Costs Impede Sustained Adherence and Access to HAART in a Clinic Population in Southwestern Uganda: A Qualitative Study
}

\author{
David M. Tuller · David R. Bangsberg • \\ Jude Senkungu • Norma C. Ware • \\ Nneka Emenyonu $\cdot$ Sheri D. Weiser
}

Published online: 13 March 2009

(c) The Author(s) 2009. This article is published with open access at Springerlink.com

\begin{abstract}
The cost of transportation for monthly clinic visits has been identified as a potential barrier to antiretroviral (ARV) adherence in sub-Saharan Africa and elsewhere, although there is limited data on this issue. We conducted open-ended interviews with 41 individuals living with HIV/AIDS and attending a clinic in Mbarara, Uganda, to understand structural barriers to ARV adherence and clinical care. Almost all respondents cited the need to locate funds for the monthly clinic visit as a constant source of stress and anxiety, and lack of money for transportation was a key factor in cases of missed doses and missed medical appointments. Participants struggled with competing demands between transport costs and other necessities such as food, housing and school fees. Our findings suggest that transportation costs can compromise
\end{abstract}

Author Contributions David Tuller, David Bangsberg, Jude Senkungu, Norma Ware, Nneka Emenyonu and Sheri Weiser contributed substantially to the conception and design of the research study. David Tuller conducted the qualitative interviews and Jude Senkungu, Nneka Emenyonu, David Bangsberg and Sheri Weiser contributed to study implementation. David Tuller and Sheri Weiser conducted data analysis and drafted the manuscript. David Tuller, David Bangsberg, Jude Senkungu, Norma Ware, Nneka Emenyonu and Sheri Weiser participated in editing and critical revisions of the manuscript.

D. M. Tuller ( $\square)$

School of Public Health, University of California at Berkeley,

Berkeley, CA, USA

e-mail: davetuller@berkeley.edu

D. R. Bangsberg · N. Emenyonu

Massachusetts General Hospital, Harvard Medical School,

Harvard Initiative for Global Health, Boston, MA, USA

J. Senkungu

Mbarara University of Science and Technology, Mbarara,

Uganda both ARV adherence and access to care. Interventions that address this barrier will be important to ensure the success of ARV programs in sub-Saharan Africa.

Keywords HIV/AIDS - Transportation - ARVs · Adherence $\cdot$ Access · Uganda

\section{Introduction}

Antiretroviral (ARV) adherence is a key determinant of clinical outcomes, including viral load suppression, emergence of drug resistance, and progression to AIDS and death (Bangsberg et al. 2000, 2001, 2006; Wood et al. 2003). In the past decade, there has been a marked expansion in the distribution of highly active antiretroviral therapy (HAART) in resource-constrained countries, as a result of international initiatives such as the US government's President's Emergency Plan for AIDS Relief (PEPFAR) and the Global Fund to Fight AIDS, Tuberculosis and Malaria. Studies from low-resource settings have reported adherence rates that are equivalent to or higher than those in resource-rich countries (Hardon et al. 2007; Laurent et al. 2002; Mills et al. 2006; Orrell et al. 2003;

N. C. Ware

Department of Social Medicine, Harvard Medical School, Boston, MA, USA

S. D. Weiser

Positive Health Program, San Francisco General Hospital,

University of California, San Francisco (UCSF), San Francisco,

CA, USA

S. D. Weiser

Center for AIDS Prevention Studies, UCSF, San Francisco,

CA, USA 
Oyugi et al. 2004; Rosen et al. 2007). These high levels of adherence have been found despite structural barriers that can exact a significant economic and emotional toll on patients with HIV and their families (Byakika-Tusiime et al. 2005; Crane et al. 2006; Hardon et al. 2007; Mills et al. 2006; Weiser et al. 2003). Yet, some experts have cautioned that high levels of adherence may not be sustainable over the long term (Gill et al. 2005).

In earlier studies in resource-limited countries, the cost of antiretrovirals (ARVs) was found to be among the most significant structural barriers to adherence (Crane et al. 2006; Ivers et al. 2005; Kumarasamy et al. 2005; Mshana et al. 2006; Safren et al. 2005; Weiser et al. 2003). Fortunately, many programs now provide ARVs free of charge, eliminating the need to pay for them as a source of concern and anxiety for program participants. However, the provision of free antiretroviral therapy has not eliminated financial barriers to adherence.

One such barrier is the cost of transportation to clinic to pick up monthly refills. The cost of transportation relative to income can be substantial, especially for those living in rural areas, and must compete with other essential expenses, such as for food, shelter or education. Several studies have found transportation costs to be a potential barrier to sustained antiretroviral treatment (Hardon et al. 2007; Mills et al. 2006; Mshana et al. 2006; Mukherjee et al. 2006; Weiser et al. 2003). However, these studies have not examined the mechanisms through which transportation costs may interfere with adherence and treatment retention, nor the strategies that patients use to cope with the added financial and emotional burdens posed by transportation costs.

Qualitative research is an important source of information about patient attitudes, experiences and feelings related to adherence and the barriers that impact it (Gill et al. 2005). We conducted semi-structured qualitative interviews in a population of HIV-positive patients receiving antiretroviral therapy in rural Uganda to understand how transportation costs are perceived, experienced and addressed by HIVpositive patients in medical care in a resource-constrained setting.

\section{Methods}

In-depth interviews exploring issues related to adherence, including the impact of transportation costs, were conducted in August and September 2007 with 41 people living with HIV/AIDS attending the Immune Suppression (ISS) Clinic at the Mbarara University of Science and Technology in Mbarara, Uganda. Mbarara is a small urban trading center in southwestern Uganda. The ISS Clinic serves as a regional distribution point for free ARVs and draws a largely rural population. A smaller number of patients are from Mbarara town or surrounding urban centers.

Participants were recruited from among patients who arrived at the clinic each morning to pick up their monthly supply of ARVs or receive treatment. Patients were selected through purposive sampling, a common qualitative research strategy that involves choosing subjects based on specific characteristics and attributes in order to ensure that a range of perspectives is represented (Creswell 1998). Our goal was to include significant numbers of both women and men, people from both rural and urban areas, and individuals in different phases of HIV disease. In addition, we wanted to interview at least ten participants not yet on HAART to explore their perspective on barriers to HAART initiation. Since clinic staff knew the personal situations of many of the patients, we requested that they seek out potential participants from all of our categories of interest. Participants received a voucher for lunch and the cost of transportation back home to compensate them for their time.

We conducted semi-structured interviews with study participants. Thirty-five interviews were conducted by one of the study investigators in conjunction with a trained interviewer-interpreter in English and Runyankole, the main regional language. Six interviews were conducted completely in Runyankole by the trained interviewer alone. Interviews lasted from $30 \mathrm{~min}$ to $2 \mathrm{~h}$, and most took place in a private room at the clinic. Interviews were conducted using a guide that included a number of open-ended questions and probes. Domains of inquiry for the interviews included barriers to HAART initiation and adherence; competing demands between food, transportation costs, school fees, and other family expenses; medical history; sexual risk-taking, and family food security and eating patterns. We probed in detail about episodes of missed or delayed antiretroviral doses, including the exact circumstances surrounding the missed or delayed doses, the patient's feelings about the missed or delayed doses, and the specific impact of transportation costs, food shortages, and any other structural factors on ARV adherence when volunteered by the participant.

All interviews were digitally recorded, translated from Runyankole into English, and transcribed. Through an initial review of the interviews, two of the study investigators identified repeated observations in the data and synthesized those into several major themes, each with a number of subordinate themes. The investigators then coded the interviews for these themes. Coding discrepancies were discussed and resolved. In the present paper we focus on transportation costs as a barrier to adherence and use selected quotations to illustrate key points.

All study procedures received approval from both the University of California, San Francisco, Committee on 
Human Research and the Mbarara University of Science and Technology (MUST) Institutional Review Board.

\section{Results}

Forty-one participants-25 women and 16 men-were interviewed for the study. They ranged in age from 24 to 57 , with a mean age of 37 for the women and 40 for the men. Twenty-three of the participants were from rural areas, six from urban areas, and 12 from peri-urban areas. Gardening and farming were the most frequent occupations. Thirty reported being on a HAART regimen for a period of time ranging from one month to several years, although many could not remember specifically when they started. Eleven had not yet initiated HAART. Of those already on HAART, 13 participants acknowledged having missed one or more doses of their ARVs since they started treatment. The remainder said they had never missed a dose.

All participants were asked about how they traveled to the clinic and how they found the money to cover transportation costs. None reported walking to the clinic on a routine basis. For five participants who lived within a few miles, the clinic was a short ride on a bus or motor-scootertaxi, known as a boda-boda, with a round-trip fare usually costing from $\$ 0.60$ to $\$ 1.50$ (about 1,000-2,500 Ugandan shillings at the exchange rate during September 2007, which was approximately \$1-1,700 Ugandan shillings). The other 36 participants lived farther from the clinicsome up to several hours away by car or public transportation-and generally reported that the round-trip fare for their monthly clinic visits was between about $\$ 1.75$ and $\$ 11.75$. The higher cost represents almost half of the mean per capita annual income in Uganda of $\$ 300$, or $\$ 25$ a month (Uganda Country Profile 2008).

\section{Non-Adherence}

The difficulty that transportation costs imposed on efforts to adhere to a regular medication schedule was a key theme that emerged irrespective of whether participants were able to maintain their ARV regimens. Even for many who reported strict compliance, transportation costs caused significant concerns and anxieties about whether or not they would be able to successfully adhere in the following month and into the future. Individuals who missed doses cited problems finding transportation money as a key reason for not being able to maintain their regimen, explaining that they were unable to afford to travel to the clinic before their supply of ARVs ran out.

A 32-year-old woman with four children said she sometimes did not have the money for transport because her husband, a trader, was often away on business. "Sometimes it is time to come for my refill and I do not have transport, so I cannot come," she said. "The time it happened, I sent my papers with someone, but they refused to give him my refill because they said I have to get it myself."

A widow who sold mats and baskets she wove from palm leaves said she once missed almost a month of ARVs because of a shortage of funds:

You may fail to get the 10,000 [shillings] to bring you here, and you end up getting maybe 1000, 2000, and when you get that little, you divert it to food and some medicine, and then wait until you get enough money to bring you to Mbarara.

Some patients cited loss of income associated with HIVrelated illness as one mechanism leading to difficulty with transportation costs. A 45-year-old father of five, who had missed weeks of medication because he could not afford transportation, blamed his difficulties on his inability to work:

Usually my transport is in such a way that by the time I get to the next appointment, I don't have money for it. And ever since I fell sick, my strength has been going down and I am very weak, and I don't have energy to go to the plantation and cut down matoke [a green plantain cultivated as a staple] for sale, or even plant some beans for sale."

Another participant, a 38-year-old woman with seven children, missed a month when she could not work, and the family's retail business also failed:

It was about the time I fell sick, and I didn't have strength to do some gardening, and it was around the same time that the store collapsed, so there was no money for transport...I was feeling very weak and I was sleeping most of the time, and I would feel that since I was missing medicine that I was supposed to be taking, I would be dying any minute.

Even for those not yet taking ARVs, anxiety over the cost of transportation caused them to wonder if they would be able to adhere to their medication regimens once they started. One woman preparing to start HAART said that lack of funds had already caused her to miss clinic appointments twice to see the doctor and pick up other medications to prevent opportunistic infections. She said she doubted that she would be able to afford monthly visits if she were to start taking ARVs:

I wouldn't have to worry so much about it, if I didn't have to think about the word 'transport.' I have a low income. It's going to be a difficult thing, because 
transport is a problem, most especially for us people staying in the rural village areas...I think it's very important to come here for the medicine, but then I can't refuse to buy books for my child so as to spare transport to come here.

\section{Difficult Choices}

Another major theme that appeared repeatedly across the sample was that transportation costs forced participants into having to make serious sacrifices in other essential arenas. Despite the above-cited examples of non-adherence, patients generally expressed their determination to sustain treatment and reported that saving money for transportation came above all else. One woman noted that she and her husband, who was also infected, "sacrifice as much as we can" to obtain the money for the round-trip fare. "It's only natural that we'd want to be alive and living," she added. "So what we do, before our medicine gets finished, we do everything to make sure that there is money for transport to bring us."

For almost all the respondents, "doing everything" to secure transportation money meant spending less on other needs. Many were deeply aware that their determination to keep their medication appointments meant less money for family essentials. One woman, a 34-year-old living with her parents since separating from her husband three years before, said she spent the money on transportation to get her medication even when she had no food: "It happens sometimes that I regret that I'm spending 500 shillings on a boda-boda when I know that back home there is nothing to eat. But then I do not have a choice."

A 44-year-old woman with four children, whose husband died in 2001, acknowledged that she also felt conflicted when she hired a boda-boda to bring her to clinic. "I feel bad when I have to spend that money on transport when I could have spent it on something else... [but] I must come to pick up my medicine," she said. "I can give up any other thing, but do not think I can give up my medicine. It would take first priority if I had to choose between it and something else." An unmarried 26year-old, who had been deserted by the father of her two children, said: "Sometimes I have to do without maybe salt, paraffin, kerosene, so that I can get the transport to come here."

Even when participants managed to pay for transportation to their monthly clinic visit, the constant search for money caused them a significant amount of psychological and emotional distress. "It's my most, most worrying problem, because every time I have to come, I usually do not have transport, and it keeps me awake most of the time," said a 35-year-old widow with five children.
In particular, respondents discussed how difficult it was for them to balance their need for transportation against the need to pay for food, school fees, and other necessities for themselves and their families. They felt forced into having to make difficult choices between unattractive alternatives. A mother of five, long separated from her husband, said her awareness of what she and her family must sacrifice because of her illness troubled her:

Yes, I think about that 20,000 [to pay for transportation], I think about the fact that if I didn't have HIV, I wouldn't have to spend that money to come here for treatment. I imagine all the other things it could have been used for, and I don't feel peace in my heart. I could hire people to do the digging, pay for school fees, buy more food. There's no way I can even think of eating chicken, fish and meat as often as I'd like when I have to get money for transport to this place.

A 46-year-old man, a farmer with five children who lived far from the Mbarara clinic, said that his fear about not being able to find transportation money every month took a definite psychological toll. "Transport...almost like drains me because sometimes we look at our situation and there is almost no way out," he said. "And in the near future we might sell our shirts so as to be able to raise the transport, since I know that without the medicine I cannot exist, and yet I do not have the money to come to pick the medicine up."

\section{Coping Strategies}

In order to save or find the money for transportation, participants either devised strategies for saving money despite the deprivations they faced, or else borrowed money to make ends meet. Some reported that they tried to put aside some portion of whatever they managed to earn, even when they or members of their family did not always have what they needed. "I do work for other people and they pay about 1,000 shillings," said a 46-year-old father of five, who needed 20 times that amount for one round-trip fare to the clinic. "Half of the payment I use to look for food, and the other half I keep. And I do that till the end of the month. The money I keep is my transport."

When he did not have enough money, said the man, he entered into an agreement with another local HIV-positive man on HAART:

We combine the money collected such that every month, only one of us can come to pick up the medicine for both of us. In case one of us does not have enough contribution towards transport, the one coming to pick up the medicine takes credit while the 
one who did not have works so as to have money to cover the other one's debt.

Another man, a 32-year-old whose wife and youngest child were also infected, said he decided to remove his children from private school to help him save the funds he needed every month for the round-trip fare. He earned money by selling produce from the family garden at a stall in the marketplace:

I plan that as the month begins I have to first earn 16,000 shillings for transport to the clinic to pick up the medicine...I always have a store, and every time I am selling, I am always planning for the month that's coming. I always make sure to save enough...You cannot really be able to determine how much money you will earn in a day and therefore how much will be saved per day, but I always try to save 500 shillings per day when the circumstances allow it.

Many respondents talked about borrowing transportation money from family, friends, and social clubs or organizations as one way they managed to access funds for clinic visits and other expenses. And those with assets reported that they sometimes had to sell their assets in order to afford transport costs, among other expenses. A 44-yearold widower with four children explained: "I just sold a piece of my plantation to my brother and was using that money for transport here, and to pay for credit, and take care of some home basics."

\section{Discussion}

Most studies among people living with HIV/AIDS on antiretroviral therapy in sub-Saharan Africa have found high rates of adherence (Hardon et al. 2007; Laurent et al. 2002; Mills et al. 2006; Orrell et al. 2003; Oyugi et al. 2004; Rosen et al. 2007; Weiser et al. 2003). Yet the presence of many structural and financial barriers to adherence, which have been documented in both qualitative and quantitative research, raises questions about whether and for how long such high rates of adherence are sustainable (Gill et al. 2005). The present study's findings confirm that even when patients have a high level of commitment to medication adherence, economic factorsin particular, the high cost of transportation for monthly clinic visits - are an important challenge to sustained treatment success. While other studies have cited transportation costs as one of the many structural barriers to treatment retention and adherence, this is the first published qualitative study to our knowledge to explore in depth the relationship between transportation costs and adherence in a low-resource setting.
The barriers imposed by transportation are multi-faceted (Ware et al. 2006). They include the direct expense of gasoline or transportation fares as well as the opportunity costs of spending hours, a whole day, or even more than one day traveling to and from clinic to pick up medication. In Uganda and other countries of sub-Saharan Africa, many people live in rural areas and must travel at significant cost in money and time to reach the hospitals or HIV clinics that distribute the ARVs free of charge. With the current volatility in oil prices, transportation costs can also change quickly, making it even harder to plan for upcoming clinic visits. One recent study found that having to travel long distances to pick up medication did not negatively impact adherence (Carlucci et al. 2008). However, the sample was drawn through a drug distribution program with prescreening requirements that selected for highly motivated patients, so whether the findings can be extrapolated to other populations remains unclear.

For participants in the current study, the need to locate transportation funds was a constant challenge. They described how they must weigh these transportation costs, which can absorb a significant chunk of their monthly income, against other necessities, either for themselves or their families. They confront a difficult dilemma: whether to spend money on obtaining the ARVs that help keep them alive or on meeting the high financial burdens of food, housing, and school. The starkness of the choice highlights the possibility that adhering to ARV medications can compromise other aspects of health and well-being, if nutrition, shelter, and education are being sacrificed in order to sustain treatment. Certain coping strategies adopted by patients may also have unintended health consequences. For example, when patients pick up ARVs for each other to save money on transportation costs, the absent patient does not receive the benefits of health counseling and other clinic services that month.

Difficulties with transportation costs can not only impede day-to-day adherence to antiretroviral therapy but can also impact retention in care and lead to significant loss-to-follow-up (Rosen et al. 2007). Rosen has noted that most studies of HAART use in sub-Saharan Africa have not included patients lost-to-follow-up when determining adherence rates, even though similar barriers, such as high transportation costs, can lead to both interruptions in treatment access and loss-to-follow-up.

Our findings support the proposition that the concept of access to medication-or lack thereof-may be a more fruitful approach to the issue of missed doses than a strict focus on adherence (Bangsberg et al. 2006; Crane et al. 2006). Researchers have discussed the importance of disaggregating two distinct-but often conflated-concepts: failure to adhere, and lack of access. When structural and financial barriers make it difficult or impossible for 
patients to access medications, the situation should not be interpreted as evidence of poor adherence skills or lack of motivation. In fact, such barriers are prime examples of what Farmer and others have referred to as "structural violence," in which societies constrain individual agency and action through the unequal distribution of power, wealth and other resources (Farmer 1999).

The distinction between failure to adhere and lack of access is important because each construct implies a different approach to intervention. As researchers have noted, interventions focused on increasing information, motivation and behavioral skills can help address causes of nonadherence within an individual's control, but reducing structural and economic barriers is essential to prevent nonadherence that arises from lack of access to ARVs.

Interventions for reducing the impact of transportation on sustaining complicated medication regimens are already being explored by community-based groups in sub-Saharan African and elsewhere (Behforouz et al. 2004; Koenig et al. 2004; Weidle et al. 2006). Such interventions include subsidizing travel costs and delivering drugs directly to the community through home-based care models, neighborhood drug dispensaries and local hospitals and primary care clinics. Other possible interventions include expanding the use of mobile clinics, strengthening support groups for people living with HIV/AIDS, and augmenting adherence counseling sessions with a discussion of transportation costs as a potential barrier to clinic attendance. Future research should focus on the effectiveness of these and other interventions to decrease barriers related to transportation costs.

There are several limitations to our study. We did not interview individuals who were lost-to-follow-up, for whom transportation might have been an even greater barrier. Most of the interviews were conducted through an interpreter by a non-Ugandan investigator, although similar themes emerged from interviews conducted by a trained investigator-interpreter from Mbarara. Despite these limitations, the extensive dialogue facilitated by the qualitative interview strategy revealed nuances of patients' perceptions, attitudes, and behavior that are hard to obtain from strictly quantitative methodologies but that are nonetheless important to consider in future development of ARV distribution programs in Uganda and elsewhere in sub-Saharan Africa.

In conclusion, our study was to our knowledge the first qualitative report to focus in depth on transportation costs as an important barrier to adherence and treatment retention in sub-Saharan Africa. Our findings suggest that: (1) patients have a high level of commitment to medication adherence; (2) the high cost of transportation for monthly clinic visits is a serious concern for many individuals and can compromise both ARV adherence and access to care; and (3) transportation costs compete with other essential personal and family needs when resources are scarce. Creative interventions to address the barriers posed by transportation costs are likely to be necessary to ensure sustained ARV adherence over the long term.

Acknowledgments The authors also wish to thank Annet Kawuma, Janet Ayebare, and Nozmu Mukiibi for their invaluable contributions to this research.

Funding sources This study was funded by NIMH K23 MH079713-01, NIMH RO-1 54907, Mark and Lisa Schwartz, the Meyers Family Foundation, the Hellman Family Awards for Early Career Faculty, and a Doris Duke Charitable Foundation Operational Research in AIDS Care and Treatment in Africa (ORACTA) grant.

Open Access This article is distributed under the terms of the Creative Commons Attribution Noncommercial License which permits any noncommercial use, distribution, and reproduction in any medium, provided the original author(s) and source are credited.

\section{References}

Bangsberg, D. R., Hecht, F. M., Charlebois, E. D., Zolopa, A. R., Holodniy, M., Sheiner, L., et al. (2000). Adherence to protease inhibitors, HIV-1 viral load, and development of drug resistance in an indigent population. AIDS (London, England), 14(4), 357366. doi:10.1097/00002030-200003100-00008.

Bangsberg, D. R., Perry, S., Charlebois, E. D., Clark, R. A., Roberston, M., Zolopa, A. R., et al. (2001). Non-adherence to highly active antiretroviral therapy predicts progression to AIDS. AIDS (London, England), 15(9), 1181-1183. doi:10.1097/0000 2030-200106150-00015.

Bangsberg, D. R., Ware, N., \& Simoni, J. M. (2006). Adherence without access to antiretroviral therapy in sub-Saharan Africa? AIDS (London, England), 20(1), 140-141. doi:10.1097/01.aids. 0000196168.50303.31.

Behforouz, H. L., Farmer, P. E., \& Mukherjee, J. S. (2004). From directly observed therapy to accompagnateurs: Enhancing AIDS treatment outcomes in Haiti and in Boston. Clinical Infectious Diseases, 38(Supp 5), S429-S436. doi:10.1086/421408.

Byakika-Tusiime, J., Oyugi, J. H., Tumwikirize, W. A., Katabira, E. T., Mugyenyi, P. N., \& Bangsberg, D. R. (2005). Adherence to HIV antiretroviral therapy in HIV+ Ugandan patients purchasing therapy. International Journal of STD and AIDS, 16(1), 3841. doi:10.1258/0956462052932548.

Carlucci, J. G., Kamanga, A., Sheneberger, R., Shepherd, B. E., Jenkins, C. A., Spurrier, J., et al. (2008). Predictors of adherence to antiretroviral therapy in rural Zambia. Journal of Acquired Immune Deficiency Syndromes, 47(5), 615-622. doi:10.1097/ QAI.0b013e318165dc25.

Crane, J. T., Kawuma, A., Oyugi, J. H., Byakika, J. T., Moss, A., Bourgois, P., et al. (2006). The price of adherence: Qualitative findings from HIV positive individuals purchasing fixed-dose combination generic HIV antiretroviral therapy in Kampala, Uganda. AIDS and Behavior, 10(4), 437-442. doi:10.1007/ s10461-006-9080-z.

Creswell, J. (1998). Qualitative inquiry and research design: Choosing among five traditions. Thousand Oaks, CA: Sage Publications, Inc.

Farmer, P. (1999). Pathologies of power: Rethinking health and human rights. American Journal of Public Health, 89(10), 14861496. doi:10.2105/AJPH.89.10.1486.

Gill, C. J., Hamer, D. H., Simon, J. L., Thea, D. M., \& Sabin, L. L. (2005). No room for complacency about adherence to antiretroviral therapy 
in sub-Saharan Africa. AIDS (London, England), 19(12), 12431249. doi:10.1097/01.aids.0000180094.04652.3b.

Hardon, A. P., Akurut, D., Comoro, C., Ekezie, C., Irunde, H. F., Gerrits, T., et al. (2007). Hunger, waiting time and transport costs: Time to confront challenges to ART adherence in Africa. AIDS Care, 19(5), 658-665. doi:10.1080/09540120701244943.

Ivers, L. C., Kendrick, D., \& Doucette, K. (2005). Efficacy of antiretroviral therapy programs in resource-poor settings: A meta-analysis of the published literature. Clinical Infectious Diseases, 41(2), 217-224. doi:10.1086/431199.

Koenig, S. P., Leandre, F., \& Farmer, P. E. (2004). Scaling-up HIV treatment programmes in resource-limited settings: The rural Haiti experience. AIDS (London, England), 18(Suppl. 3), S21-S25. doi: 10.1097/00002030-200406003-00005.

Kumarasamy, N., Safren, S. A., Raminani, S. R., Pickard, R., James, R., Krishnan, A. K., et al. (2005). Barriers and facilitators to antiretroviral medication adherence among patients with HIV in Chennai, India: A qualitative study. AIDS Patient Care and STDs, 19(8), 526-537. doi:10.1089/apc.2005.19.526.

Laurent, C., Diakhate, N., Gueye, N. F., Toure, M. A., Sow, P. S., Faye, M. A., et al. (2002). The Senegalese government's highly active antiretroviral therapy initiative: An 18-month follow-up study. AIDS (London, England), 16(10), 1363-1370. doi: 10.1097/00002030-200207050-00008.

Mills, E. J., Nachega, J. B., Bangsberg, D. R., Singh, S., Rachlis, B., Wu, P., et al. (2006). Adherence to HAART: A systematic review of developed and developing nation patient-reported barriers and facilitators. PLoS Medicine, 3(11), e438. doi: 10.1371/journal.pmed.0030438.

Mshana, G. H., Wamoyi, J., Busza, J., Zaba, B., Changalucha, J., Kaluvya, S., et al. (2006). Barriers to accessing antiretroviral therapy in Kisesa, Tanzania: A qualitative study of early rural referrals to the national program. AIDS Patient Care and STDs, 20(9), 649-657. doi:10.1089/apc.2006.20.649.

Mukherjee, J. S., Ivers, L., Leandre, F., Farmer, P., \& Behforouz, H. (2006). Antiretroviral therapy in resource-poor settings. Decreasing barriers to access and promoting adherence. Journal of Acquired Immune Deficiency Syndromes, 43(Suppl. 1), S123S126. doi:10.1097/01.qai.0000248348.25630.74.

Orrell, C., Bangsberg, D. R., Badri, M., \& Wood, R. (2003). Adherence is not a barrier to successful antiretroviral therapy in
South Africa. AIDS (London, England), 17(9), 1369-1375. doi: 10.1097/00002030-200306130-00011.

Oyugi, J. H., Byakika-Tusiime, J., Charlebois, E. D., Kityo, C., Mugerwa, R., Mugyenyi, P., et al. (2004). Multiple validated measures of adherence indicate high levels of adherence to generic HIV antiretroviral therapy in a resource-limited setting. Journal of Acquired Immune Deficiency Syndromes, 36(5), 1100-1102. doi:10.1097/00126334-200408150-00014.

Rosen, S., Fox, M. P., \& Gill, C. J. (2007). Patient retention in antiretroviral therapy programs in sub-Saharan Africa: A systematic review. PLoS Medicine, 4(10), e298. doi:10.1371/ journal.pmed.0040298.

Safren, S. A., Kumarasamy, N., James, R., Raminani, S., Solomon, S., \& Mayer, K. H. (2005). ART adherence, demographic variables and CD4 outcome among HIV-positive patients on antiretroviral therapy in Chennai, India. AIDS Care, 17(7), 853-862. doi: 10.1007/b138963.

Uganda Country Profile. (2008). United Kingdom Department for International Development. http://www.dfid.gov.uk/countries/ africa/uganda.asp. Accessed 3 Oct 2008.

Ware, N. C., Wyatt, M. A., \& Bangsberg, D. R. (2006). Examining theoretic models of adherence for validity in resource-limited settings. A heuristic approach. Journal of Acquired Immune Deficiency Syndromes, 43(Suppl. 1), S18-S22. doi:10.1097/ 01.qai.0000248343.13062.4b.

Weidle, P. J., Wamai, N., Solberg, P., Liechty, C., Sendagala, S., Were, W., et al. (2006). Adherence to antiretroviral therapy in a home-based AIDS care programme in rural Uganda. Lancet, 368(9547), 1587-1594. doi:10.1016/S0140-6736(06)69118-6.

Weiser, S., Wolfe, W., Bangsberg, D., Thior, I., Gilbert, P., Makhema, J., et al. (2003). Barriers to antiretroviral adherence for patients living with HIV infection and AIDS in Botswana. Journal of Acquired Immune Deficiency Syndromes, 34(3), 281-288. doi: 10.1097/00126334-200311010-00004.

Wood, E., Hogg, R. S., Yip, B., Quercia, R., Harrigan, P. R., O'Shaughnessy, M. V., et al. (2003). Higher baseline levels of plasma human immunodeficiency virus type 1 RNA are associated with increased mortality after initiation of triple-drug antiretroviral therapy. The Journal of Infectious Diseases, 188(10), 14211425. doi:10.1086/379201. 